the planes of least dense packing, or more densely packed planes with a high concentration of vacant sites, and by the addition of traces of electronegative substances. The data available suggest that the requisite metallic properties are to be found in metals and alloys having holes at the top of the $d$ - or $f$-bands. (When both the cation radius and $I$ are large, as with some saturated molecules, ionization may more easily occur indirectly by electron transfer with some more easily formed cation, for example, $\mathrm{H}^{+}$.)

By similar reasoning it is demonstrable that negative ion formation requires the same geometry for the active centre, but a small electron exit work function and a large negative value of $\left(d \log _{e} g(\varepsilon) / d \varepsilon\right)$ at the Fermi surface. It will be promoted by traces of electropositive additions.

The concentration and rate of formation of a covalently bonded species depend similarly on the bond strength. Pauling's older concepts ${ }^{5}$ show that the bond strength decreases as the $d$-orbital content of the hybridized orbitals diminishes, whereas according to his later scheme $e^{6}$ the number of empty 'atomic' orbitals drops to zero as the $d$-band is filled. The number of unused surface 'bonding' orbitals continues to fall as more $s$-electrons are added to the metal. Since these orbitals are required for occupation by electrons in the process of chemisorption, a rapid fall in activity occurs at the alloy composition where the $d$-band is filled, followed by a much slower decline with further increase in the electron : atom ratio. The band theory of metals leads to the same conclusion, since the number of canonical forms of low excitation energy of the chemisorbed complex must increase with increasing electron-level density, leading to enhanced resonance energy and greater bond strength. As entropy can be put proportional to the logarithm of level density, it is suggested that the entropy of activation decreases as bands of high level density are filled. Real chemisorptive bonds involve Coulomb forces, exchange forces and Van der Waals forces, and it is convenient that when the mixed bond involves a tendency to positive ion formation, all three vary in the same way with the properties of the $d$-band holes.

These relationships between the electronic structure of the solid and the rate and energy of formation of chemisorbed species can now be applied to the prediction and explanation of catalytic activity in reactions controlled by the rate of formation of ions or radicals or covalently bonded complexes, or wherein the rate-controlling step depends on the concentration of such species on the surface. By this means catalytic activity can be directly related to the energy and density of levels at the Fermi surface. The correlation explains the activity trends in binary and multicomponent alloys, where the rate of fall in activity with added $s$-, $p$-metals increases with the valency of the latter; it provides an interpretation of the changes in activity at the phase boundaries in Hume-Rothery alloys; and it goes a long way to explain the much-disputed magneto-catalytic effects of Hedvall and the observed effects of order-disorder transformation in alloys. Catalyst poisoning is also elucidated; it is now clear that the poison may be effective not only by obscuring the surface, but also through its effect on the electron work function of the solid and on the unfilled electron levels and orbitals within it.

Extension of the same principles to catalysts which are semi-conductors or insulators is more difficult, but considerable progress has been made. The same considerations show that positive ions are most easily formed on defect conductors or on insulators with easily reducible cations, particularly when the sub. stance contains a stable component with cation defects. Conversely, negative ions are most easily formed on excess semi-conductors or on insulators with easily oxidized cations or where stable anion defects are present. (It is possible that excess semiconductors under high hydrogen pressures function as metal catalysts.) Insulators-which neither accept nor donate electrons easily-function by chemisorbing reactants as positive and negative ions; proton exchange mechanisms are prominent, and these proceed most readily at cation defects.

In discussion, Dr. D. D. Eley (Bristol) presented experimental data on the ortho-para hydrogen conversion at the surface of palladium-gold alloys, which clearly indicated a rapid drop in activity at about 50 atomic per cent of added gold, that is, at the composition corresponding to the complete filling of the $d$-band in palladium. The drop in activity is accompanied by a large rise in activation energy and a decrease in the frequency factor, to be contrasted with the more common parallel changes in these variables. The fact that hydrogen poisons the reaction on pure palladium would appear to indicate that hydrogen itself can provide electrons to fill up the $d$-orbital of the palladium.

Dr. E. B. Maxted (Bristol) discussed evidence which showed that poisoning of platinum catalysts by transitional metal ions occurs only when the added ion has all five orbitals of a $d$-shell immediately preceding $s$ - or $p$-valency shells electronically occupied. Regularities also exist in the correlation between the catalytic activities and magnetic susceptibilities of the platinum metals.

Dr. J. S. Anderson (Harwell) presented some data on the electrical properties of semi-conducting zinc oxide which suggested that at very low partial pressures of oxygen the excess zinc atoms may aggregate into small regions of two-dimensional metal.

${ }^{1}$ Dowden, Research, 1, 239 (1948).

${ }^{2}$ Beeck, Smith and Wheeler, Proc. Roy. Soc., A, 177, 62 (1940).

${ }^{3}$ Beeck, Rev. Mod. Phys., 17, 61 (1945).

${ }^{4}$ Lennard-Jones, Trans. Farad. Soc., 28, 333 (1932).

"Pauling, "The Nature of the Chemical Bond"'(1942).

'Pauling, Rev. Mod. Phys., 20, 112 (1948).

\section{COLONIAL GEOLOGICAL SURVEY WORK}

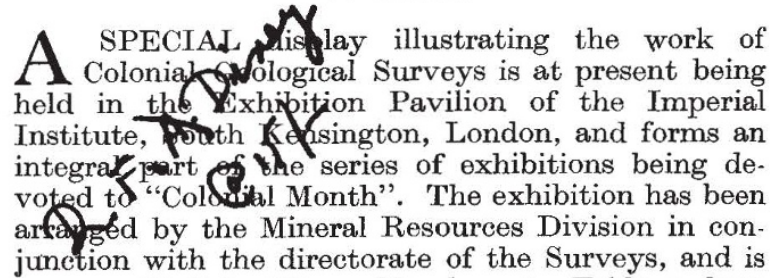
open until July 20 on Mondays to Fridays from 10 a.m. to 4.30 p.m., and on Saturdays from 10 a.m. to 1 p.m.

Since January 1, 1947, all official matters relating to the development of Colonial geological survey work have been the responsibility of Dr. F. Dixey, director of Colonial Geological Surveys and geological adviser to the Secretary of State for the 
Colonies. Apart from the directorate in London, the Colonial Geological Surveys comprise twelve departments or divisions in active operation in Colonies of East, Central and West Africa, in the High Commissioner Territories of Southern Africa, in the Colonies of the Caribbean Region, and in the Far East. As soon as personnel can be found for them, additional geological surveys will commence in the West Indies, the Middle East and the Western Pacific ; arrangements are in view also for the limited examination of five other Colonies. The existing surveys vary considerably in strength and in age: some of them were established early in this century, and these have already played a very important part in developing the mineral wealth of the Colonies; whereas one new survey, in the British territories in Borneo, has been established during the current year. At present there are about seventy-five geologists in the Colonial Service; but this number will be increased considerably in the near future, as provision has been made for a total strength of nearly two hundred within the next few years.

The exhibition illustrates the basic work of Colonial geological mapping, the geologist's contribution to the development of mineral deposits and water supplies, and the work in London of the Mineral Resources Division. For each Colonial geological survey department, the most recent geological map of the whole territory is displayed, together with examples of large-scale maps, and, in some cases, photographs depicting the geologist's life in the field. The wide scope of Colonial geology is emphasized by an extensive selection of maps and publications, which range from economic memoirs dealing with specific mining fields to scientific studies, such as those of the lacustrine sediments of the Nyasan Rift Valley, the palaeontology of British Somaliland and Nigeria, or the petrology of volcanic rocks from Uganda, igneous intrusions and carbonatites from Southern Nyasaland, and pegmatites in central Nigeria.

Under the heading "The Mineral Wealth of the Colonies", a series of maps and photographs illustrates the important service of the geological surveys to the mining industries. The significance of this work for Colonial progress is apparent from the fact that the value of Colonial mineral production is now nearly $£ 100$ million per annum, the leading items being tin (Malaya, Nigeria, etc.), copper (Northern Rhodesia), petroleum (Brunei, Trinidad), and gold (Gold Coast, etc.). Here we find a selection of geological maps of well-known mining areas where bauxite, coal, copper, diamonds, gold, manganese, tin, etc., are produced, accompanied by photographs of some of the mines. The large geological map of Northern Rhodesia forms an interesting item in this section, as it was prepared privately by mineral concession companies and represents the work of no less than 167 geologists drawn from many parts of the world. The search for oil is illustrated by views of the producing oilfields of Trinidad, Brunei and Sarawak, and of an exploratory well being drilled by the Geological Survey of Uganda.

The vital importance of the development and maintenance of adequate water supplies in many Colonies, and the wide range of geological and engineering problems this involves, is brought out by a display of publications on water supplies together with photographs and maps.

A general exhibit shows examples from Tanganyika of different types of geological map : namely, a de- tailed map of a mineral area, a large-scale degree sheet designed ultimately to cover the territory on a systematic grid, and a small-seale provisional geological map of the country as a whole. The funda. mental task of deciphering the stratigraphic history of little-known countries is illustrated, in the case of British Guiana, by a series of rock specimens accompanying the provisional geological map and a boldly speculative vertical section across the country. Photogeology is represented by a series of aerial photographs selected from several Colonies to illustrate the value of this technique in elucidating geological structures, this being one of the specialist services already provided by the Directorate.

On April 1 this year, the Mineral Resources Department of the Imperial Institute became the Mineral Resources Division of Colonial Geological Surveys. A consequence of this change is that the long experience acquired by this Department in the evaluation of economic minerals from all parts of the Commonwealth is now focused more sharply on the mineral development of the Colonies. Photographs of the chemical, mineralogical, spectrographic and ceramic laboratories give an indication of the facilities afforded by the Division, and exhibits of typical work carried out are presented. These include the results of technical trials on Sierra Leone lignite and clays; examples of bricks and pottery made from the latter ; analyses and washing tests on Tanganyika coals; trials of pozzolanic building materials from St. Vincent; and analyses of Nyasaland bauxites. Examples of special publications are also displayed, including the well-known "Statistical Summary of the Mineral Industry", of which a new volume is to appear shortly. Other publications shown include the series of articles on the geology and mineral resources of the Colonies, with their specially prepared geological and mineral maps, which have recently appeared in the Bulletin of the Imperial Institute.

Small special exhibits deal with rare minerals, and with the early history of geological work in the Colonies. The selection of rare minerals includes six of the score of minerals which were first discovered and described from Colonial territories, and comprise nigerite (the new tin mineral from Nigeria), lusakite and tarbuttite from Northern Rhodesia, bismutotantalite from Uganda, and potarite (palladium amalgam) and merumite (hydrated chromic oxide) from British Guiana. Above this exhibit are photographs of large alluvial diamonds, including the largest existing diamond in the world, found a few years ago in Sierra Leone, where diamonds were first discovered by the Geological Survey Department.

The historical section shows a few examples of early geological maps by pioneer explorers, and includes J. R. Logan's map of Singapore published in 1851 ; Dr. Livingstone's crude geological section across Africa on the route by which he crossed the continent during 1853-56; and the first geological map of East Africa from Joseph Thomson's expedition of 1878-80. Maps of Trinidad (1860) and Jamaica (1865), published in memoirs of the Geological Survey of Great Britain, mark the first official geological work in the Colonies. Finally, two maps of Nigeria illustrate the results of the Imperial Institute Mineral Surveys of the period 1903-14, which were the forerunners of the present geological surveys in both Nigeria and Nyasaland. 